This item was submitted to Loughborough's Research Repository by the author.

Items in Figshare are protected by copyright, with all rights reserved, unless otherwise indicated.

\title{
The pivotal role of rapid manufacturing in the production of cost effective customised products
}

PLEASE CITE THE PUBLISHED VERSION

PUBLISHER

(C) Inderscience

VERSION

AM (Accepted Manuscript)

LICENCE

CC BY-NC-ND 4.0

\section{REPOSITORY RECORD}

Tuck, Christopher, and Richard J.M. Hague. 2019. "The Pivotal Role of Rapid Manufacturing in the Production of Cost Effective Customised Products”. figshare. https://hdl.handle.net/2134/5653. 
This item was submitted to Loughborough's Institutional Repository (https://dspace.lboro.ac.uk/) by the author and is made available under the following Creative Commons Licence conditions.

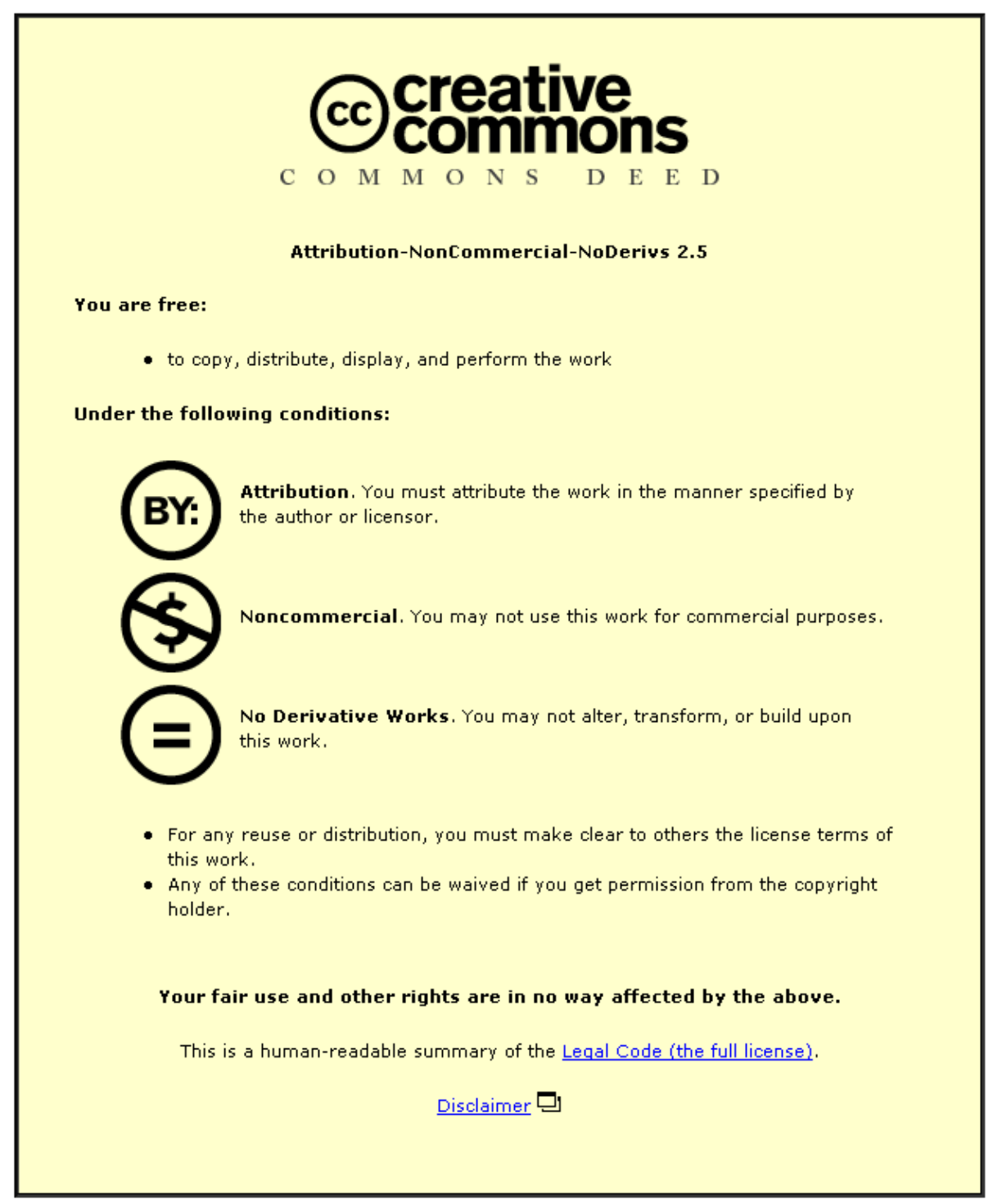

For the full text of this licence, please go to: http://creativecommons.org/licenses/by-nc-nd/2.5/ 


\title{
The Pivotal Role of Rapid Manufacturing in the Production of Cost Effective Customised Products
}

\author{
Christopher Tuck and Richard Hague
}

\author{
Author Contacts: \\ Dr Christopher Tuck, Research Associate \\ Rapid Manufacturing Research Group \\ Wolfson School of Mechanical and Manufacturing Engineering \\ Loughborough University \\ Loughborough \\ Leicestershire \\ LE11 3TU \\ UK \\ +44(0) 1509227568 \\ c.j.tuck@lboro.ac.uk \\ www.lboro.ac.uk/departments/mm/research/rapid-manufacturing/research/people/Tuck.html \\ Dr Richard Hague, Senior Lecturer \\ Rapid Manufacturing Research Group \\ Wolfson School of Mechanical and Manufacturing Engineering \\ Loughborough University \\ Loughborough \\ Leicestershire \\ LE11 3TU \\ UK \\ +44 (0) 1509227619 \\ r.hague@lboro.ac.uk \\ www.lboro.ac.uk/departments/mm/research/rapid-manufacturing/research/people/hague.html
}

\section{Abstract:}

The concept of Rapid Manufacturing (RM) is emerging from the so-called Rapid Prototyping technologies where additive rather than subtractive techniques will be used to make parts or even completed assemblies. As no tooling is required, one of the main benefits of RM will be the ability to make cost-effective custom products that could all be entirely individualised to a particular consumer or user. Thus, Rapid Manufacturing is the enabling technology for true, cost effective custom manufacturing and has the potential to revolutionise the design and manufacturing worlds. This paper will introduce results from a current research project that is being undertaken at Loughborough University looking into the effects that will occur to the logistics and supply chain infrastructure with the advent of RM. 


\section{Introduction}

The high cost of tooling is one of the most prohibitive factors that limit product development and manufacture. The automotive sector, for example, is increasingly becoming oriented towards niche products and thus the cost of manufacturing tooling has to be amortised across fewer vehicles, consequently increasing the cost per unit. This is especially true and relevant for the relatively low volume, niche and custom vehicles that the UK specialises in. The high cost of tooling greatly limits the product design, range of materials and the complexity \& custom-aspects of a product. For most companies, there are regular compromises in design so that components can be manufactured by alternative methods, often in less-suitable materials because it is impossible to justify the cost of tooling. Off-the-shelf solutions are frequently used that give the necessary economies of scale but these can often detract from the design intent. Also, even when tooling can be justified, there is often a long lead-time for their delivery that can greatly affect the time-to-market of a product and thus the competitiveness of companies.

To reduce the impact of tooling costs, mass-production is employed to amortise the cost of tools over a high number of parts. However, mass production is not viable for many companies and also, customers are increasingly desiring or expecting to have affordable 'custom' products. The lacocca Institute (lacocca, 1991) and a report of Next Generation Manufacturing (NGM, 1997) have highlighted a requirement for flexibility, agility and mass-customisation. However, the implementation of mass-customisation will affect materials choice and requires a costly change in the manufacturing infrastructure that leads to a consequent need for rapid reconfiguration of tooling, manufacturing, logistics and servicing facilities.

True (or full) customisation is not feasible at present for the mass-market and thus mass-customisation is currently achieved by 'modularisation' (Salvador et al. 2002), i.e. the production of modules that can be bolted together in varying configurations that gives the economies of mass production but allows some customisation in the product. By using management techniques such as postponement, the decision of how the final product is configured can be delayed to allow for greater degrees of customisation. Standard manufacturing techniques are still employed (for the modules) and therefore there is still the need for costly tooling.

However, a step-change in manufacturing is beginning, in that the materials and methods by which products are manufactured in the future will radically alter. The current use of moulds and dies to give items their form whether they are parts for cars or space shuttles (Bampton, 1998), mobile phone covers or breakfast cereals, will be superseded by the emerging technologies that come under the Rapid Manufacturing banner. Rapid Manufacturing (RM) is evolving from the now mature Rapid Prototyping (RP) technologies that produce parts directly from a 3D CAD model without the use of tools (Jacobs, 1996). As the processes and materials improve over the next 10-years or so, much of this technology will develop into use within mainstream manufacturing. The advent of Rapid Manufacturing will have profound implications on all aspects of product development and manufacture. In conventional manufacturing, there is a direct link between the complexity of a part and its cost. In Rapid Manufacturing, not only is complexity independent of cost but also the RM techniques are able to produce virtually any geometry. Compounding the fact that as high volumes do not need to be manufactured to offset the cost of tooling then the possibilities for affordable highly 
complex, custom parts becomes apparent. In theory, each part that is produced could be a custom part.

Rapid Manufacturing offers the potential to change the paradigm of manufacturing, service and distribution with opportunities for producing highly complex, custom products at low cost, at locations at or outside the conventional factory - possibly by the distributor, retailer or customer. Rapid Manufacturing will affect manufacturers and customers alike. For manufacturers, costs will be dramatically reduced as no tooling is required and for customers, affordable, complex, individualised products will be cost effectively made that can be configured to personal use thus giving the potential for much greater product satisfaction. For true customisation to occur, the involvement of the customer in the design process is not only desirable but also essential in order to satisfy their specific requirements. As RM machines process 3D CAD data, in order to truly individualise a product there will be a need to digitise all or part of a customer's body profile. But the location of where this design-customisation is performed and how is it to be realised and how it can be executed in a timely and cost-effective manner are all questions that need addressing. How the customer interacts with the 3D data is also far from clear as current 3D CAD systems are expert systems that require significant training. It is feasible that a customer, with the aid of web-based technology or dealer located software could radically alter many aspects of a vehicle from interior trim to body shape. However, what freedom or limitations the customer has in what can or can't be changed is also important to consider in terms of CE marking and homologation issues.

Linked to the customisation issue is that if no tooling is required, then the opportunity arises to change the manufacturing location. Even if no customisation is required Rapid Manufacturing offers significant advantages to niche, low-to-mid volume companies. Rapid Manufacturing has the ability to greatly extend management and organisational philosophies such as mass-customisation to previously unimagined levels and will also extend the postponement principles to allow the true customisation of a product that would be unachievable by any other method.

Rapid Manufacturing is the enabling technology for true, cost effective custom manufacturing and has the potential to revolutionise the design and manufacturing worlds. This paper will introduce results from a current research project that is being undertaken at Loughborough University looking into the effects that will occur to the logistics and supply chain infrastructure with the advent of RM.

\section{Literature Review}

\subsection{Rapid Manufacturing}

The concept of Rapid Manufacturing is based on the evolution of existing Rapid Prototyping technologies, and is concerned with the direct manufacture of parts and components using additive manufacture techniques (Hague et al. 2003, Rooks 2002, Hopkinson and Dickens 2001). These techniques have some important advantages that are linked to the technology's modus operandi. The concept of additive manufacture requires that components be built from data files derived from common CAD software, and are manufactured by adding materials together rather than traditional, destructive or subtractive manufacture, where material is taken away through processes such as machining (Griffiths 2002). A large advantage lies in the ability to produce highly complex parts that require no tooling, and thus, a large reduction in the costs of manufacture could be possible especially for low volumes 
(Hopkinson and Dickens 2001). As with all new and novel technological developments some questions have yet to be answered, these questions form the principle drivers for the uptake of RM as a process. These questions can be broadly defined as implications on design methods and practices (Hague et al. 2003), process and materials improvement, and the management, organisation and implementation of RM.

Rapid manufacturing technology has its roots in the development of rapid prototyping technology The definition of RM is not that parts are produced rapidly, but are manufactured by a different process to conventional manufacturing methods. The general principle is that material is added together to form the desired component, hence the more accurate terminology, additive manufacture. Current processes are based on RP technology developed over the past two decades, and are predominantly based on layer-by-layer forming of products. Two such processes are stereolithography (SL) and laser sintering (LS) (Jordan and Michel, 2000). For the purposes of this paper the production method is unimportant, however the repercussions for the manufacturing industry are. Both these processes allow the production of complex free form geometries in the product or component leading to the ability to produce products, that using conventional manufacturing techniques would be either impossible or extremely expensive to manufacture (Hague, 2003). Another important ramification of RM is the ability to produce low volume products that are commercially viable.

\subsection{Low Volume Production by RM}

The possible impact of RM on the way current manufacturing businesses operate and future profitability could be at the very least, profound (Anon 2001). The development of tool less manufacture of parts, an inherent property of RM, will make the economic production of smaller quantities more viable (Hopkinson and Dickens 2001, Griffiths 2002). Indeed it is envisaged that RM will allow the economic production of single units, thus changing the paradigm for manufacturing organisations considerably. Walter et al. (2002) have studied the effect RM could have on the supply of spare parts to the commercial aircraft industry. Many of the spare parts used in this industry are used infrequently and the timing of the need for these parts can be erratic. However, rapid availability of these parts is required at all times, as aircraft on the ground lose money. By producing these items on demand using RM methods this cost of holding stock can be reduced and thus the company can make a significant saving by employing rapid manufacturing. This example of reducing the cost of stock by reducing the number of value added stock items (i.e. finished spare parts) could also have an impact on other manufacturing industries, as it is possible to economically produce low volumes or even single volume items. Therefore, a profound impact could be envisaged on mass customisation practices. Indeed taking this paradigm a step further, RM could be thought of as the company warehouse, providing parts on time, every time but requiring significantly less infrastructure and providing a nil stock holding cost for parts and assemblies. Indeed the only stock that will be required will be the raw materials required for production using $\mathrm{RM}$.

\subsection{Mass Customisation}

Consumers are becoming increasingly refined in their tastes and desires for new products. One method for tackling the requirements of the consumer is to provide a mass customisation service (Pine II, 1993). The production of low cost and high variety products has become a necessity in many product areas and, in particular, the automobile sector. The use of mass customisation in order to differentiate products 
adds significant value to the consumer, by producing a product that satisfies the consumers need for individualisation of the product to their specification. It is perhaps difficult to envisage a world where "you can have any colour as long as it is black" (Pine II, 1993) would be an acceptable phrase.

The impact of mass customisation on the production environment has been profound, and could be thought of as a key driver for the agile supply chain paradigms prominence in manufacturing business thinking worldwide (Naylor et al. 1999). The experience of mass customisation has been particularly focused on the automobile sector, where in order to create value and compete with lower-cost imported vehicles, western manufacturers have found it necessary first to change their operational model to compete with far east suppliers and secondly seek competitive advantage in the area of mass customisation.

Work has been carried out into the concept of mass customisation in the context of the vehicle manufacturing industry (Alford et al. 2000). The article focuses on optional customisation of high volume manufacturing. The authors define three strategies for customisation in the automotive sector, these being, form, optional and core customisation. Core customisation has direct customer involvement in the design process of the vehicle, this method of customisation, requires a low volume product due to the nature of the manufacturing processes possible and the interaction of the customer. Conversely, optional customisation is focused on high volume manufacture of vehicles with the addition of customised options chosen by the purchaser. These options are then integrated into the vehicle during assembly. The concept of form customisation is to change the form of the standard product at the distributor, for example, changing the finance package, service and warranty specifications. These three customisation strategies have defining characteristics; they require different properties in the manufacturing process (low, medium or high volume) or require different perception of the customer as to what customisation really is.

The perception of customisation needs definition before the aspects of customisation can be discussed. The Cambridge on-line dictionary defines "customise" as:

\section{"to make or change something according to the buyer's or user's needs"}

The definitive aim for customisation of a vehicle should surely be that based on core customisation, whereby the customer specifies the vehicle in such a way, that the vehicle meets their needs completely. This can only occur, at present, with low volume goods, as the knowledge and skills to produce such a product are not easily transferable to a mass production environment. That is, until the successful demonstration of RM production methods. A recent paper (Fox, 2003) has outlined the increasing trend towards mass customisation and its consequences for engineering. $A$ number of important points are developed and should be discussed. Firstly when companies are aiming to offer one to one marketing, issues will occur at the very core of the product development cycle, i.e. the design. As the customer can specify what the products form will be, certainty in the design is not realised until the production of the component is complete and approved by the customer. Other issues follow from this; the product and design may never be used again for other customers. The argument continues to say that these issues (large but not insurmountable) do not have to be considered if a mass custom approach is taken. Mass customisation removes these problems by providing parts, components and sub-assemblies in the same way that products have been made during the industrial age. However, the main difference occurs in their assembly to form the final product. In reality mass customisation is 
enabled through the modularity of the components used, and the information gleaned from the customer to provide them with their ideal product. Referring back to Alford's work on mass customisation in the automotive sector, this type of customisation should be referred to as optional customisation. Fox goes on to discuss the ability to offer customised products in various sectors, and concludes that the properties of the materials necessary to produce the product have a significant impact on whether the marketing strategy of personalisation will be successful. For example, cosmetics made up of formless materials whereas cars are formed from assemblies and subassemblies. The constraint of the materials that are used to produce a tailored product means that currently, it would not be possible to produce a one off car in the same time as a mass custom vehicle at the same price. While this my be considered a sensible position in today's manufacturing environment it may not be necessarily true if we consider the advances being made in the field of RM (Rooks, 2002).

\section{The benefits of using RM for customisation}

Rapid manufacturing offers many benefits to manufacturing industries, however it is firstly important to define what current manufacturing paradigms exist as all products require production of some kind this will enable the identification and discussion of the benefits that will be applicable to future mass customisation industries.

\subsection{Lean production}

The lean paradigm of supply chain management encompasses the idea of reducing waste throughout the supply chain. The waste may occur as time or materials for example, resulting in some of the more popular supply chain models of recent times such a s Just-In-Time manufacture (Slack et al. 1998). In further work by Cox (Cox $1999 b)$ a summary of the eight lean supply chain characteristics have been given.

These were:

1. Strive for perfection in delivering value to customers.

2. Only produce what is pulled from the customer just-in-time and concentrate only on those actions that create value flow.

3. Focus on the elimination of waste in all operational processes, internally and externally, that arise from the overproduction, waiting, transportation, inappropriate processing, defects and unnecessary inventory and motion.

4. Recognise that all participants in the supply chain are stakeholders and that we must add value for everyone in the business.

5. Develop close, collaborative, reciprocal and trusting (win-win), rather than arms length and adversarial (win-lose) relationships with suppliers.

6. Work with suppliers to create a lean and demand driven logistics process.

7. Reduce the number of suppliers and work more intensively with those given a preferred long-term relationship.

8. Create a network of suppliers to build common understanding and learning about waste reduction and operational efficiency in the delivery of existing products and services.

The eight features above show the aims of a lean supply chain methodology. These general characteristics can be achieved through different methods. For example, a popular methodology for eliminating waste in stock holding and time would be to introduce a Just-In-Time delivery schedule with suppliers. These initiatives require the development of long term relationships with suppliers, as it would be difficult to instigate these changes in supply methods that influence the entire companies 
operations without a trusting relationship. These strategic characteristics have been developed from the pioneering work of Toyota in the 1970s and 80s (Slack et al. 1998). Many of Toyota's main competitors and many other industries worldwide have copied this philosophy. Its success at reducing costs and adding value to the supply chain resulted in the great surge of the Japanese manufacturing industry in the late twentieth century.

However, the lean paradigm relies on some fundamental market principles for it to be effective in a given market and can therefore be determined unsuitable for many products. These principles (Fisher 1997) are primarily concerned with aspects of demand choices and demand patterns. The lean paradigm should suit products that have a long product lifecycle, low margin, low product variety and accurate forecasting of demand and generally where the market order winner is cost. These characteristics are not indicative of the final mass-customised product, but might represent the modules that currently make up the customised product. Unpredictable demand can have drastic effects on upstream suppliers; one such effect is known as the "Bullwhip" effect and was first identified by Forrester (Forrester, 1961). In principle the bullwhip effect stems from consumer demand patterns, fluctuations in demand are magnified down the supply chain (upstream) with ever increasing volatility (Mason-Jones et al. 2000, Towill 1997, Forrester 1961). However, this effect can be minimised through the selection of a complimentary supply chain methodology for different types of product. The difference in products and therefore customers has been clearly explained by the supply chain methodology selection matrix shown in Figure 1.

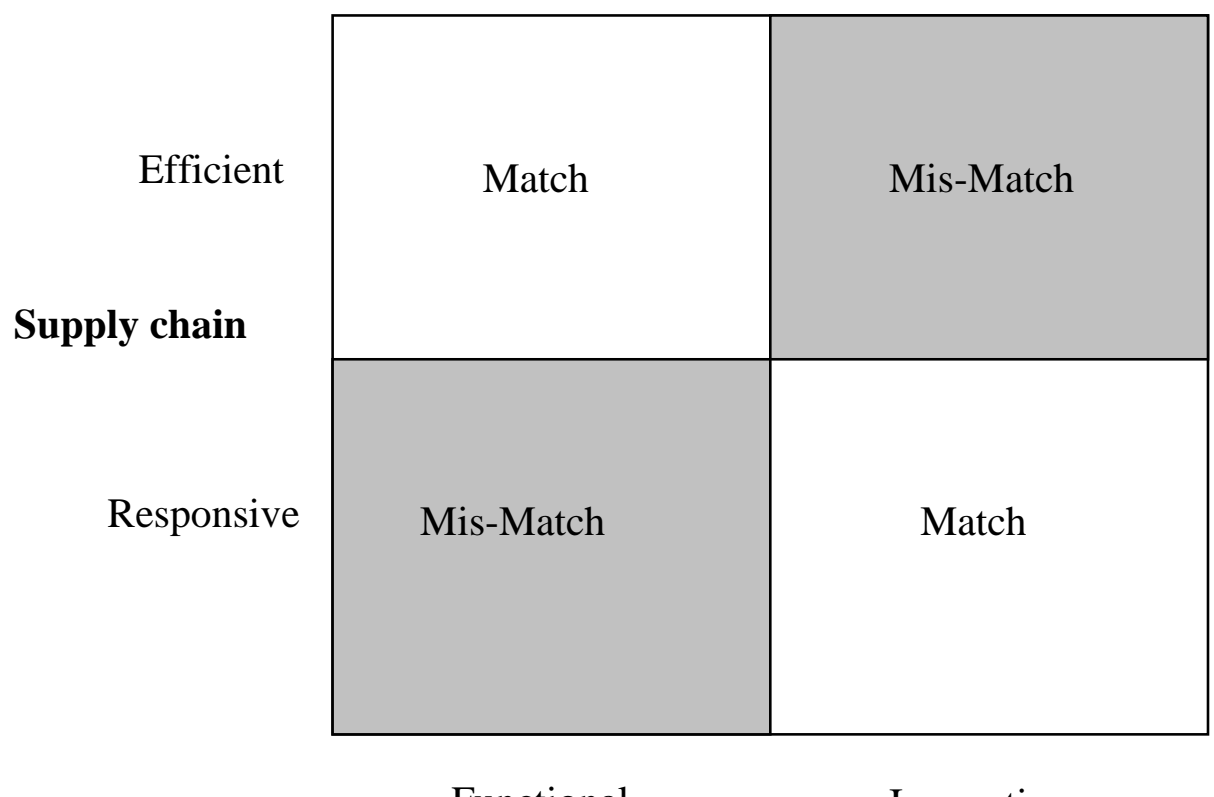

Functional Innovative

Product Type

Figure 1. Product, supply chain matrix (Source: Fisher 1997).

For commodity products that have a stable demand profile the use of efficient supply chain and thus, those that reduce waste will be more effective. However, a second paradigm exists in order to cater for more innovative products with shorter product lifecycles - the agile paradigm. Figure 1 shows the correct selection of manufacturing paradigm to product (or market) type. Considering the impact that RM will have on this 
matrix it could be conceived that no mis-match will occur. Rapid manufacturing is both efficient and responsive for custom, low and medium volumes currently and as such for the bespoke industry this will provide a platform for lean and agile production.

\subsection{The Agile Paradigm}

Naylor has defined the term agility in his discussion of lean, agile and leagile supply chains (Naylor et al. 1999),

"Agility means using market knowledge and a virtual corporation to exploit profitable opportunities in a volatile market place."

Agile supply chains work on a different set of operational methodologies. Agility focuses on lead time compression, rather than the elimination of waste. The use of flexible production methods allows fast reconfiguration of processes to cope with consumer demand. It is the variability of consumer demand that defines the motive for the agile manufacturing paradigm. For these reasons the agile paradigm is suited to products that have a short lifecycle, such as fashionable goods, compared with lean production's focus on commodity production. The market order winner for agile supply chains is no longer cost but availability (Mason-Jones et al. 2000). As such the driver for successful implementation of an agile supply chain would be market information, the forecasting of demand. Thus the information regarding a customers preferences drive the pull of products from the manufacturing environment, with an associated increase in cost to accommodate the inevitable increase in costs associated with changes in build methods and products.

It could be said that the advent of the agile supply chain, has been necessary because of the increased demands of the customer being placed on to the producer (Maskell 2001). The sophistication of customer desires and tastes has lead to goods becoming increasingly fashion oriented with styles and colours becoming a market order winner rather than product function. One methodology for enabling this "value-adding" activity has been the concept of mass customisation. The ability to define a customer's needs and wants, relies on the availability of suitable information on customer preferences and the ability within the agile organisation to provide these services in a timely manner. Thus, the emphasis on production has changed from one based on costs of production to knowledge and information availability, and hence, the skills and knowledge of the organisation are now paramount (Maskell 2001).

\subsection{Leagility and Postponement}

The concept of leagility brings together the concepts of lean and agile supply chains in order to appropriate greater value from the supply chain. The leagile paradigm aims to develop the lean supply chain (with it's efficient practises) into an organisation where it would be possible to take these cost advantages and use them to gain market share in more volatile markets normally served by agile supply chain management practices. The defining attributes of lean and agile supply chains are presented in Table 1 . The table gives an indication of what types of product are suited to the paradigm and also the market characteristics for those products. It is clear from the table that these two methodologies suit very different markets and that the application of the wrong paradigm in the wrong market could have a large detrimental effect on the efficiency of the business and its future profitability. 


\begin{tabular}{|l|l|l|}
\hline Distinguishing Attributes & Lean Supply & Agile Supply \\
\hline Typical products & Commodities & Fashion goods \\
\hline Market place demand & Predictable & Volatile \\
\hline Product variety & Low & High \\
\hline Product lifecycle & Long & Short \\
\hline Customer drivers & Cost & Availability \\
\hline Profit margin & Low & High \\
\hline Dominant costs & Physical costs & Marketability costs \\
\hline Stockout penalties & $\begin{array}{l}\text { Long term } \\
\text { contractual }\end{array}$ & $\begin{array}{l}\text { Immediate and } \\
\text { volatile }\end{array}$ \\
\hline Purchasing policy & Buy goods & Assign capacity \\
\hline Information enrichment & Highly desirable & Obligatory \\
\hline Forecasting mechanism & Algorithmic & Consultative \\
\hline
\end{tabular}

Table 1. Comparison of lean and agile supply chain operators (Source: MasonJones et al. 2000).

The development of leagile supply chains has been discussed by a number of authors (Naylor et al. 1999, Childerhouse and Towill 2000, van Hoek 2000). In order to produce an effective leagile supply chain the amalgamation of lean and agile supply methods must be integrated effectively to produce a supply chain that can provide down-stream (towards the customer) responsiveness and up-stream stability. This can be achieved through postponement (van Hoek 2001). In the leagile supply chain, the application of a de-coupling point allows the two systems to be integrated and defines when and where to implement lean or agile manufacturing practices. This de-coupling point effectively removes the down-stream volatility of customer demand and acts as a buffer to those processes up-stream, postponement delays certain activities within the supply chain until the customer order has been received. The delay can be used to postpone the addition of value to a product until the order has been received and therefore reduce costs of stockholding through providing a generic platform that can be manipulated to any future customer order. This also has the added advantage of reducing obsolescence of stock and increasing levels of responsiveness when customer orders are received. This can lead to a competitive advantage where, through the reduction in costs and increased response to customer demands, the market is better served.

\section{The impact of RM on supply chains and subsequently mass customisation}

The impact of RM on supply chain practices could be the most profound, as it not only impinges on current methodologies but also on the members within the supply chain. A diagram of the lean, agile and leagile supply chain paradigms are presented in Figure 2. As all products or services have a supply chain, their production will be affected by the introduction of RM. To use mass customisation as an example, previous best practice has been to use the leagile paradigm to appropriate more value from the supply chain in terms of time and costs. 
1)

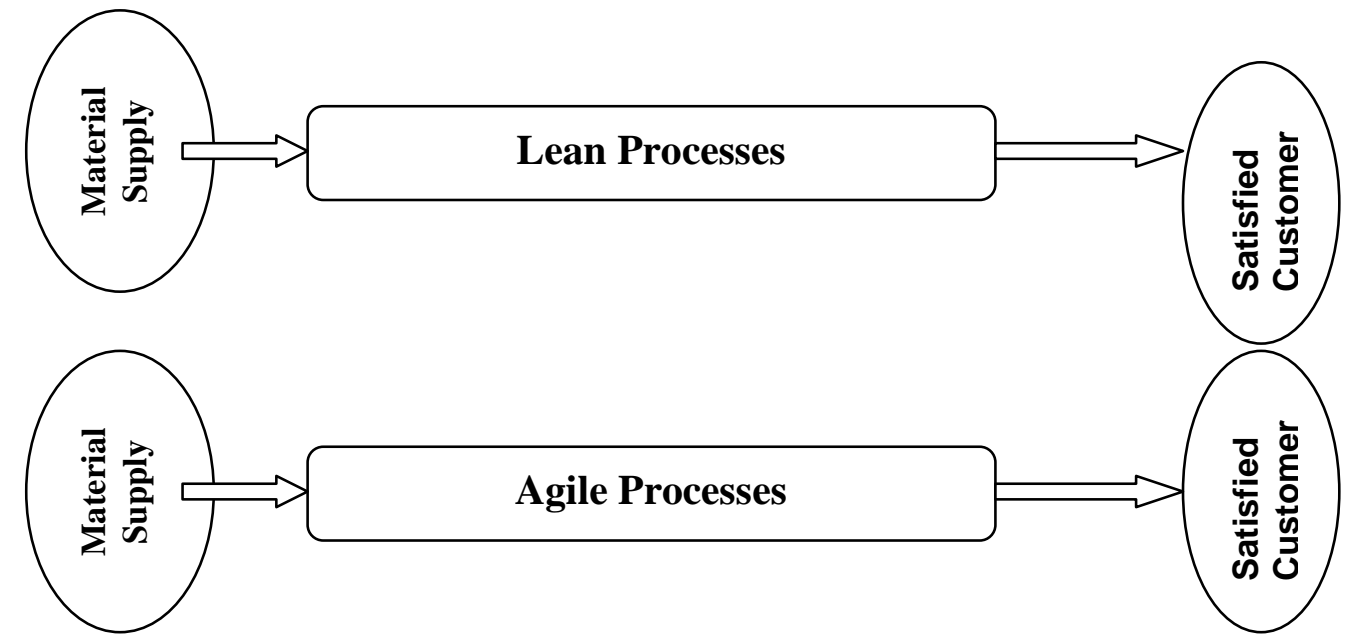

3)

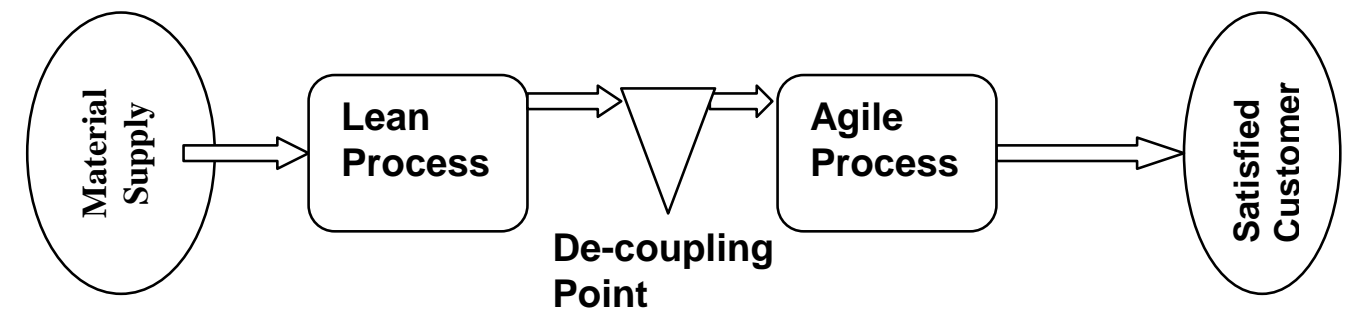

Figure 2. Schematic of 1) lean 2) agile and 3) leagile supply chain theories. (Source Mason-Jones 2000).

\subsection{Impact on supply chains}

Firstly, the impact of RM on the lean manufacturing paradigm will be discussed. As mentioned in section 3.1, the lean manufacturing paradigm relies on some fundamental operators for successful implementation. These definitions have been defined by numerous authors, (Mason-Jones et al. 2000, Childerhouse and Towill 2000, Fisher 1997) and have been compared with agile supply chain operators. Table 1 shows the operators in comparison to those for agile supply.

It can be clearly seen that the key driver for a lean supply chain is cost. The dominant costs are those inherent in the process, and have been defined as all production costs including such items as stock and logistics.

The application of RM as mentioned in section 2.2, allows the economic production of single parts. For this reason, what would be the need to hold stock, if, as should be possible with RM, they can be produced, on time every time to the product design specification? The only requirements to produce the parts through RM will be the design parameters (in an electronic format such as a CAD model) and the raw material. As such the only stock that might need to be held is that in the design and no value added raw material. The production of parts to order quickly and economically should result in no part stock holding unless this is desired for reasons of agility. For fully customised parts (i.e. those designed for or by a specific customer) no stock can be held, apart from guaranteed repeat business, but by implementing RM no stock of any part need be held. Therefore the production of a customised part will be the same as a 
standard one, thus enabling lean production of any product the company wishes to manufacture.

The impact on agile or responsive supply chains will be no less profound and those effects seen on lean supply chains will impinge on the agile paradigm too. As discussed previously (section 3.2) the agile supply chain works best for volatile products, such as those that are fashionable or have a short product lifecycle. The advent of RM would mean that lean production in a responsive manner could become a reality without the need for the "leagile" concept. In effect the manufacturing machine would become the de-coupling point, with orders only pulled off at the request of the customer. With this concept, there would be no stock outs, as all products could be produced to order, plus the threat of obsolescent stock would be negated as the only stock necessary to hold would be raw material and design data.

\subsection{Location of manufacture}

It must be stressed that the production of parts through RM will change the manufacturing paradigm from that of skilled labour operating machinery and forming a large portion of part cost, to one where the burden of cost is transferred to the technology or specifically the RM machine and materials. A further driver for the reduction of costs may be in the product design, for example the RM process may make traditional designs obsolete, by reduction in the need for assemblies, thus one process production may provide cost savings for certain parts and components (Hague et al. 2003).

Due to all these elements the production of parts could be brought back in house to the manufacturer. This will have another drastic effect on the cost of logistics. It may no longer be necessary to ship goods in, either internationally or nationally. These drivers will all affect the costs of production, and thus allow supply chains practising lean methodologies to become leaner.

As the only requirements for production are a machine, raw material and data, with minimal requirements for skilled operators, where will RM products be produced? To take advantage of the characteristics of RM the placing of RM plants should be local to where demand occurs. This would lead to reduction in logistics to the customer, thus reducing delivery costs and time, much in the JIT mould. Taking this concept further for the automobile industry, the plant could be placed trackside (i.e. next to the production line) producing parts at the required location as necessary, or for retro fitting at dealer locations, the RM machine could be based at the dealer. Locating at the dealer offers a number of advantages, in that, customers may be able to buy-in to the concept more readily, and if coupled with the necessary design capability, design and produce and fit bespoke products at the dealer.

For more consumable products the development of hub based manufacturing units placed strategically around a locality will be able to offer fast delivery for customers for any product, without the need for the retailer to hold stock of the item, thus reducing necessary floorspace, warehouse and logistics cost, among others.

In summary, RM could offer the first truly leagile supply chain paradigm, providing goods at low cost through the benefits of lean principles with the fast re-configurability and response time required in volatile markets. The production of goods through RM could lead to reductions in stock levels, logistics costs, component costs (through 
reduction in assembled components) and increase the flexibility of production, through the ability to produce products to order in a timely and cost effective fashion.

\subsection{Impact of RM on Mass Customisation}

The area of customisation discussed in section 2.3 was generally concerned with the concept of mass customisation (Pine II 1993). As discussed, this method uses standard products as a base for customisation of certain characteristics of the product. This method allows added value to be attributed to a product, but how can this be improved, and what role will RM play?

Considering the core customisation concept described by Alford et al. (2000), where the customer has intimate involvement with the vehicle in production and design, RM could have an important role. The automobile industry offers numerous options on their products from colour of bodywork to seat fabric, and the finance deal that the customer is offered. These customisation issues are not considered as core customisation and in an article by Fox (Fox 2003), it was suggested that core customisation of cars was not yet possible. But, taking into account the advantages of rapid manufacturing, this may now be possible (Loch et al. 2003). The ability to produce complex structures from digital data taken from or designed with the customer could easily be manufactured and used on that customer's vehicle. Rapid manufacturing could offer true core customisation on two levels.

The first level of customisation would be that based on customer preference, this maybe to improve the aesthetics of part or components to the customer's specification. The second level, involves the customer more intimately, by digitally capturing the customer's body shape it may be possible to provide the customer with body fit parts, for example, customised seats and seat back, to provide a more comfortable environment.

The production of body fit parts and core customisation is not novel, however, the process of design and production would involve a great deal of skill in the production of the parts and hence a large expense. With the advent of RM the production method and processes involved for customised parts would not change from part to part. Thus, the economic argument for providing this core customisation method would be improved.

\section{Conclusion}

In conclusion this paper has attempted to outline some of the effects on supply chain methodologies and principles that may occur with the advent of rapid manufacturing and their subsequent impact on the production of mass or fully customised products. The impact of RM will lead to the economic production of single units, and as demonstrated by other authors the economic production of low to medium volume products. The use of RM will enable the worlds first truly flexible manufacturing unit able to produce a part of almost any geometry and complexity whilst being able to economically produce a single unit of the desired product.

What has become clear is that, RM has the ability to change or modify these paradigms greatly. The opportunities available for reduction in costs of production, through the natural rationalisation of logistics, labour, stock holding and the ability to deal with unstable demand patterns are all apparent. The ability to remove these costs could also affect the manufacturing environment on a global scale, by returning 
manufacturing to the country of origin, as labour costs are no longer a burden. Rapid manufacturing could realise the first truly flexible, and JIT supply chain paradigm, that can respond to customer demand and changes in taste and design with ease.

Additionally, the introduction of rapid manufacturing could lead to increased value in products through the realisation of truly customised production. Though many questions remain to be answered on how the development of RM and full customisation can be implemented, the impact of this technology on the manufacturing environment will be profound.

The impact for the mass customisation community will be that, those products which you may not have been able to produce, either because the market was too small, (one to a few thousand units) or the design was far too complex.

Put simply, no market will be too small, no part too complex and manufacturing will be able to offer a complete customer solution on time and at reasonable cost.

\section{References}

Alford, Sackett and Nelder "Mass customisation - an automotive perspective" International Journal of Production Economics, Vol 65, 2000, pp. 99-110.

Anon "Survey: The solid future of rapid prototyping" The Economist, Vol 358, Issue, 8214, pp. S49 - S51.

Bampton, C., Solid Freeform Fabrication (Rapid Manufacturing) for Liquid Fuelled Rocket Engines, Boeing Rocketdyne Propulsion and Power Systems, TCT Conference, Nottingham, 1998

Childerhouse and Towill "Engineering supply chains to match customer requirements" Logistics Information Management, Vol 13, No 6, 2000, pp. 337-345.

Cox "A research agenda for supply chain and business management thinking" Supply Chain Management: An International Journal, Vol 4, No 4, 1999, pp. 201-211

Cox "Power, value and supply chain management" Supply Chain Management: An International Journal, Vol 4, No 4, 1999, pp.167-175.

Fisher "What is the right supply chain for your product?" Harvard Business Review, Vol 75, No 2, 1997, pp.105 - 116

Forrester "Industrial Dynamics" MIT Press, 1962, Boston, MA

Fox "Recognising materials power" Manufacturing Engineer, April 2003.

Griffiths "Rapid manufacturing - the next industrial revelution" Materials World, Vol 10, No 12, 2002, pp. 34-35.

Hague Campbell and Dickens "Implications on design of rapid manufacturing" Proceedings of the Institution of Mechanical Engineers Part C: Journal of Mechanical Engineering Science, Vol 217, 2003, pp. 25 -30.

Hopkinson and Dickens "Rapid prototyping for direct manufacture" Rapid Prototyping Journal, Vol 7, No 4, 2001, pp 197 - 202/ 
Iacocca Institute, 21st Century manufacturing Enterprise Strategy. 21st century Manufacturing Enterprise Strategy Ed S Goldman and K Preiss. Vol 1 and 2, 1991, Bethlehem, Pennsylvania: Iacocca Institute, Lehigh University, 58.

Jacobs, P.F. Stereolithography and other RP\&M Technologies - From Rapid Prototyping to Rapid Tooling. 1996. ISBN 0-87263-467-1

Jordan and Michel "Next Generation Manufacturing, Methods and Techniques" John Wiley and Sons, 2000, pp. 166 and 167

Loch, Sommer, Schafer and Nellassen "Will rapid manufacturing bring us the customised car?" Automotive World Knowledge, 10 March 2003.

Mason - Jones, Naylor and Towill "Engineering the leagile supply chain" International Journal of Agile Management Systems, Vol 2, No 1, 2000, pp. 54 - 61

Maskell "The age of agile manufacturing" Supply Chain Management: An International Journal, Vol 6, No. 1, 2001, pp. 5-11

Naylor, Naim and Berry, "Leagility: Integrating the lean and agile manufacturing paradigms in the total supply chain" International Journal of Production Economics, Vol 62, 1999, pp. $107-118$.

NGM Next generation Manufacturing: A Framework for Action. 1997, Bethlehem Pennsylvania: Agility Forum 705.

Pine II "Mass Customisation - The new frontier in business competition" Harvard Business School Press, 1993, Boston, MA

Renault F1 website :

http://www.renaultf1.com/en/poweredby/team/partners/3dsystems/news.php?name=en /news/p_7121.html

Rooks "Rapid manufacturing advances at Loughborough" Assembly Automation, Vol 22, No 4, pp. 333-336

Salvador, Forza, Rungtusanatham "Modularity, product variety, production volume and component sourcing: Theorizing beyond generic prescriptions" Journal of Operations Management, Vol 20, 2-2, pp. 549-575

Slack, Chambers, Harland, Harrison, and Johnson "Operations Management" $2^{\text {nd }}$ Edition, 1998, Pitman Publishing, pp. 474.

Van Hoek "The thesis of leagility revisited" International Journal of Agile Management Systems, Vol 2, No 3, 2000, pp. $196-201$.

Van Hoek "The rediscovery of postponement a literature review and directions for research" Journal of Operations Management, Vol 19, 2001, pp. $161-184$

Walter, Holmström, Tuomi "Rapid manufacturing and its impact on supply chain management"http://www.tai.hut.fi/ecomlog/publications/rapid_manufacturing.pdf 